\title{
Partial Immersion Program for Saudi Bilinguals
}

\author{
Sumayyah Qaed Alsulami ${ }^{1}$ \\ ${ }^{1}$ English Language Institute, King Abdul-Aziz University, Saudi Arabia \\ Correspondence: Sumayyah Qaed Alsulami, English Language Institute, King Abdul-Aziz University, Saudi \\ Arabia. E-mail: somayyah81@gmail.com
}

\author{
Received: October 12, 2016 Accepted: January 18, 2017 Online Published: January 22, 2017 \\ doi: 10.5539/elt.v10n2p150 URL: http://dx.doi.org/10.5539/elt.v10n2p150
}

\begin{abstract}
English is taught as a foreign language in Kingdom of Saudi Arabia. Although the government tries gradually to integrate teaching English in all grades: secondary, intermediate and elementary, learning English is still limited and need more developing. This essay is a brief review about bilingualism in Saudi education. This essay will be divided into three sections. The first section will describe the Saudi bilingual context through three dimensions: language competence, late bilingualism, and individual bilingualism. The following section will define bilingualism with regard to the Saudi context. The last section will discuss the appropriate educational program for Saudi bilinguals and the implications of this educational program incorporating Arabic and English.
\end{abstract}

Keywords: bilingualism, Saudi, partial-immersion, education, English

\section{Introduction}

In this age of globalization and information technology, most countries, including Saudi Arabia, have to cope with scientific, technological, political, social, academic, and even linguistic changes. Globalization and information technology are taking the world by storm, and they have certain codes, purposes, systems, standards, and languages. Nowadays, the English language is the lingua franca of the modern world. English is the main medium of world trade, global universities, and information technology. Saudi Arabia is not isolated from all these changes around the world. Therefore, the Saudi government realized the need to integrate the English language into the school curriculum as a foreign language beside Arabic, which is the only official language that is used in the constitutions, courts, media, homes, streets, schools, etc. Speaking English has increased in the last few years because of many reasons that stimulate Saudis' desire to learn English. First, travelling outside Saudi Arabia is one of the reasons that speaking a global language like English helps in communicating with people in other countries. Another reason for speaking English is that there are foreign workers in different places such as hospitals, shops, restaurants, and hotels who usually know English only, so it is hard to interact with them in Arabic. Studying in certain university majors, such as medicine or engineering, is the third reason that motivates students to speak English. Therefore, this essay will focus on the best program and method to develop teaching two languages.

\section{Saudi Context}

\subsection{Language Competence}

According to Baker (2011), Saudi bilinguals in high school are able to speak and write in Arabic actively but their ability is limited in English. They can speak short sentences and write with less competence. So they have receptive ability and they could be passive bilinguals. In addition, Saudi bilinguals use Arabic in a wide range of places such as home, school, among friends, and in the street whereas English is limited to certain situations like traveling, among certain friends, on the internet, at the hospital, and at certain restaurants. Arabic is the dominant language, and this excludes Saudi bilinguals from being balanced bilinguals. Saudi bilinguals are best described as incipient bilinguals because they have a well-developed language, which is Arabic, while English is in the early stage of development. The culture of a second language is not a target for Saudi bilinguals because they have their own distinct culture and religious beliefs that are not consistent with other cultures. So far, Baker's terminology in bilingualism shows part of the language competence in Saudi bilinguals. Skutnabb-Kangas and Toukomaa (1976) suggested a difference between surface fluency and academically related aspects of language competence. Surface fluency can include the ability to hold a simple conversation in the street or at a shop and will be acquired quickly, e.g., in two or three years by second language learning. However, it is not enough to 
have conversational language competence to cope in the curriculum. Academically related language competence in a second language, which requires five to eight years or longer to be acquired, is a high level of competence. Saudi bilinguals have the surface fluency in English but they still need more improvement to acquire the academically related aspects of language competence.

\subsection{Late Bilingualism}

Saudi bilinguals in this situation are sequential bilinguals, which means they acquired Arabic when they were children and later after the critical period for language learning. Although in this context the bilinguals have improved their speaking of English as a second language, they are considered as late bilinguals. The most debated factor in second language is the age. The common belief is that the lower the age at which a second language is learnt, the greater the long-term proficiency in this language. However, Hakuta (2001) gives hope to the student in the Saudi context who started learning English late by arguing that:

The evidence for a critical period for a second language acquisition is scanty, especially when analyzed in terms of its key assumption. There is no empirically definable end point, there are no qualitative differences between child and adults learners, and there are large environmental effects on the outcomes. . . . The view of a biologically constrained and specialized language acquisition device that is turned off at puberty is not correct.

In addition, Marinova-Todd,Marshall, and Snow (2000) state that language learning is not influenced by age, but mainly because it is associated with social, psychological, educational, and other factors that may affect L2 proficiency, not because of the critical period that restricts the possibility of language learning in adulthood.

\subsection{Individual Bilingualism}

There are many reasons to consider Saudi bilinguals as individual bilinguals. The first reason is the cognitive development that the teacher and government in general are seeking to prompt the educational values. Cook (2002) argues that as many subjects such as geography, history, chemistry, physics, and mathematics have been taught to prompt intellectual fitness and stamina, so modern language learning has been encouraged as a way of sharpening the mind and developing the intellect. Similarly. Bialystok (2007) also argues that the experience of controlling attention to two languages promotes the development of executive control processes in childhood, which are essentialtoall cognitive life. What is important for Saudi bilinguals in this study is that Bialystok provides the evidence that bilinguals will sustain cognitive control advantages through adulthood and bilingual older adults will be protected from diminution of these processes with aging.

The second reason to consider individual bilinguals is the self- confidence that Saudi bilinguals will obtain by speaking English. In the recent context, Saudi bilinguals are incipient bilinguals who are looking for more development in their second language to be able to communicate, interact, and form relationships with English speakers everywhere.

The third and most important reason to involve Saudi bilinguals in individual bilingualism is learning English for careers and employment. Learning English will give students many opportunities first in choosing their majors at universities in Saudi Arabia, such as medicine and engineering, which require high levels and scores in English to be admitted. Moreover, learning English will open the doors to find the appropriate jobs. Multinational companies in Saudi Arabia search for employees who are competent in both Arabic and English to represent them. These reasons classify Saudi bilinguals as individual rather than societal.

\section{Bilingualism}

The definitions of bilingualism have been varied, numerous, and usually contrasting. The idea is that the bilingual phenomenon as a situation and a process is complicated and it is hard to define it in one simple definition. Thus, many definitions from different dimensions can describe the bilingual phenomenon in the Saudi high school level, but before it is defined some concepts related to bilingualism should be explained. These terms are language ability, language achievement, language competence, language performance, language proficiency, and language skills. Language skills tend to refer to highly specific, clearly definable components such as spelling, handwriting, and grammar. Conversely, language competence is a general and broad concept, used specifically to describe an inner and mental representation of language; such competence usuallyrefers to an underlying system inferred from language performance. Language performance is the outward evidence for language competence, e.g., conversation or a language test. Language ability is defined as a general latent disposition that determines the eventual language success. In addition, language proficiency is usually used as a synonym for language competence and sometimes to means a specific assessment of outcome from language testing. On the other hand, language achievement is the outcome of formal instruction (Baker \& Jones, 1998). 
Macnamara (1967) suggests that a bilingual is a person who can possess a minimal competence in only one of the four languages skills: speaking, listening comprehension, reading, or writing in a language other than his or her mother tongue. This is consistent with the Saudi situation. Saudi bilinguals have a good competence in two skills — speaking and reading — but they still struggle in listening and writing in their second language, English. Moreover, Beatens-Beardsmore (1982) defines bilingualism as a necessary or optional means of effective communication between two or more "worlds" using two language systems. Similarly, Titone (1989) says:

Bilinguality implies a degree of communicative competence sufficient for effective communication in more than one language; effectiveness requires the ability to correctly understand the meaning of messages and/or the parallel ability to produce intelligible messages in more than one code.

In the Saudi context, bilinguals are able to communicate in both languages but "effective" may not describe their communication in English. They can communicate effectively in Arabic but the degree of effectiveness in communication in English is limited.

Furthermore, Hamers (1981) states that the term "bilingualism" refers to the state of a linguistic community, since two languages are in contact, with the result that two codes can be used in the same interaction and a number of individuals are bilinguals. This refers to societal bilingualism while the concept of bilinguality is more appropriate to describe Saudi bilinguals. This bilinguality is the psychological situation of individuals who have access to two linguistic codes as a means of social community, and the degree of access might vary along a number of dimensions, including cognitive, psychological, social psychological, social, sociolinguistic, sociological, sociocultural, and linguistic. These dimensions were discussed with regard to individual bilingualism. Another dimension is the language choice in defining bilingualism. A bilingual speaker has three choices: speak language A, speak language B, or speak a combination of A and B in a single utterance (Hoffman, 2001). A Saudi bilingual can speak Arabic, English, or a combination of Arabic and English. This combination can be defined as code switching, which has recently spread in Saudi Arabia, particularly between teenagers at high school. Bloomfield (1942) proposed one of the famous definitions of bilingualism, which is that in the extreme state of foreign language learning, the speaker becomes proficient, which makes him undistinguishable from the native speaker in his environment, and this proficiency in a foreign language is not associated with the loss of a native language. Although this definition does not describe Saudi bilinguals, this is the target for them in the future.

\section{Immersion Bilingual Education}

Many researchers have focused on foreign language acquisition in school settings. In the past thirty years, there has been a shift away from teaching a language in isolation and toward incorporating language and context. These researchers have introduced various forms of programs that are related to bilingualism. Some of these forms are not quite effective, such as transitional, mainstream with foreign language teaching, and separatist. In contrast, there are more effective programs that are considered as strong forms, such as immersion, maintenance, and dual language (Baker, 2011).

Immersion bilingualism was invented in 1960 in Canada for English speakers, who are the language majority students, to acquire French by being taught in both languages. English-speaking parents who wanted their children to become bilinguals encouraged this innovation, so they would acquire more skills for the job market. Then, this bilingual educational approach was exported successfully to many countries. An immersion program is a method of teaching bilinguals by using a second language as a medium of classroom instruction. In this program, bilinguals study some school subjects, such as math, science, and social studies. The main aim of this type of bilingual education is to enhance bilingualism, in particular the second language competence and proficiency, as well as the students' first language. It differs from one country to another regarding to two factors: age and the amount of time spent in immersion. With regard to age, the program depends on the age at which the learner commences the experience, so there are three types of this program: early, middle, and late immersion. The early immersion may be at kindergarten or during infancy, the middle immersion is at age nine to ten years, and the late immersion appears at the secondary level. In addition, an immersion program is divided into total and partial immersion regarding the amount of time spent in immersion. Total immersion means teaching with $100 \%$ immersion in the second language, while partial immersion includes $50 \%$ immersion in the second language (Baker, 2011).

Since 1965, the immersion bilingual education has spread rapidly in Canada as well as parts of Europe (Rebuffot, 1993). The experiment at St. Lambert was a success. The educational objectives, attitudes, and achievement were met and were not hampered by the immersion experience. Lambert and Tucker (1972) state the outcomes of this immersion bilingual education: 
The experimental students appear to be able to read, write, speak, understand and use English as well as youngsters instructed in English in the conventional manner. In addition, and at no cost they can also read, write, speak and understand French in a way that English students who follow a traditional program of French as a second language never do.

Moreover, in Catalonia, Artigal (1993) found that Spanish-speaking students who followed an immersion program not only became fluent in Catalan, but also improved their Spanish. In the Catalan immersion curriculum, students perform as well as their peers who do not follow an immersion program and sometimes they outperform them. In addition, an immersion program in Finland is the idea of a politically active women's group at Vaasa which gained political credibility for incorporating Swedish- and Finnish-speaking children. Lauren (1994) notes that integrating third and fourth languages, such as English and German, can produce multilingual fluency.

Swain and Johnson (1997) and Swain and Lapkin (2005) state a number of the main characteristics and the variable features of immersion programs for children who are learning French as a third language. These characteristics are: (1) the language in the immersion program is the medium of instruction; (2) the immersion curriculum is parallel to the local and first language curriculum; (3) there is school support for developing the students' languages; (4) additive bilingualism occurs by using this program; (5) generally, the exposure to the immersion language is limited to the classroom; (6) students enter the immersion program with limited or nonexistent levels of proficiency in the immersion language; (7) all the teachers are bilinguals; and (8) the classroom culture needs to respect and recognize the different culture of students' languages. In addition, the variable features of immersion programs are: (1) the grade level at which the program is taught; (2) the extent of the immersion program, partial or total; (3) the proportion given to the first and second language in content-based teaching at different levels; (4) whether there is continuity from the primary to the secondary level or occasionally from the secondary to a further level; (5) the amount of language support given to students from their first to their target language; (6) the resources that are used in both the first and the second language and the teachers' ability to use them; (7) the commitment of students, teachers, administrators, and politicians to the immersion program; (8) the students' attitudes towards the second language culture; (9) the status of the second language; and (10) what counts as success in the immersion program.

Immersion bilingual education is an appropriate program to promote teaching English in Saudi Arabia. In this context, high school is the level at which Saudi bilinguals will experience this education program. This determines that the program is a late immersion program. Because this is the first time the bilinguals are exposed to this kind of program, the proportion of immersion will be partial. This means $50 \%$ of the subjects will be taught in Arabic, such as Arabic, religion, and social science, and 50\% will be taught in English, such as English, chemistry, physics, biology, and mathematics. The program is occasional because it starts at the secondary level to university. The English culture is not a target for Saudi bilinguals, and the Saudi culture is dominant in this program. The object of this program is to develop English as a second language. This is what the teachers should convey to students by teaching two languages without losing their identity or imitating the western culture, which does not meet with their culture. The teachers should be bilinguals and trained to teach by using the immersion program method.

After four years of learning English as a foreign language, starting from grade six, it is time to implement an immersion program at the high school level from ages 16 to 18 . The main reason to choose this time for an immersion program is that the Saudi universities are using English text resources in most of their courses, such as science, health science, medicine, and engineering. This makes students struggle when they enter the university and results in low performance. Furthermore, Saudi students are highly motivated to learn English as a global language to be able to communicate with all people around the world. Implementing an immersion program in high school is the first step; then it can be implemented in intermediate and primary school in the future.

Using code switching in bilingual immersion classrooms is controversial. Jacobson (1979) prefers code switching for pedagogical uses such as capturing the student's attention, conceptual development, and lexical enrichment. In addition, he proposes that intersentential switching, which is between sentences—one sentence in L1 and the other in L2 - is the only type used. Gonzalez and Maez (1980) recommend that the students do not switch due to lack of repertoire in the other language. In Saudi immersion programs, the teachers accept the oral intersentential code switching from students only to encourage them and raise their self-confidence. The teachers also use it to attract their students' attention. Over time the amount of code switching will be reduced to concentrate and develop English as a second language. In other words, the amount of leakage from Arabic to English will start high and become lower over time. For example, a teacher will allow students to use code 
switching in Arabic in group discussion with their classmates, and after four or five weeks the teacher will try to help students who switch to explain in English so as to reduce leakage of Arabic in English.

It is hard to assess Saudi bilinguals in one semester. The assessment would take a long period. Various types of tests depend on the skill that needs to develop. For communication, communicative language testing is a good choice. It involves acting some scenes about communicative situations in real life. Dictation, reading comprehension, and writing tests are a number of quizzes to test academic skills. Oral proficiency can be measured by recording storytelling or interviews. Speed of reaction in a word association task, dictation of words using both Arabic and English, and time taken to read a set of words in both languages are tests of balance in bilingualism. Funny and interesting games will be used in every class to keep students interested.

\section{Conclusion}

The Saudi government has included English in the educational curriculum. Teaching English as a foreign language did not enrich students' knowledge nor develop their skills. Shifting to bilingual education is the most effective method in teaching more than one language. Saudi students are bilinguals to some extent, so the partial late immersion bilingual program is designed in this essay to help them to cope with difficulties in learning English. Students can be assessed through numerous tests that help in developing students' skills and ability.

\section{References}

Artigal, J. M. (1993). Catalan and Basque immersion programmes. In H. Beatens-Beardsmore (Ed.), European models of bilingual education. Clevedon, England: Multilingual Matters.

Baker, C. (2011). Foundations of bilingual education and bilingualism (5th ed.). Clevedon, England: Multilingual Matters.

Baker, C., \& Jones, S. (1998). Encyclopedia of bilingualism and bilingual education. Clevedon, England: Multilingual Matters.

Beatens-Beardsmore, H. (1982). Bilingualism: Basic principles. Clevedon, England: Tieto Ltd.

Bialystok, E. (2007) Cognitive effects of bilingualism: How linguistic experience leads to cognitive change. International Journal of Bilingual Education and Bilingualism, 10(3), 210-223. https://doi.org/10.2167/beb441.0

Bloomfield, L. (1942). Outline guide for the practical study of foreign languages. Special Publications of the Linguistic Society of America. Baltimore: Linguistic Society of America.

Cook, V. J. (2002). Background to the L2 user.In V.J. Cook (Ed.),Portraits of the L2 user (pp. 1-28). Clevedon, England: Multilingual Matters.

Gonzalez, G., \& Maez, L. F. (1980). To switch or not to switch: The role of codeswitching in the elementary bilingual classroom. In R. V. Padilla (Ed.), Ethno-perspectives in bilingual education research: Theory in bilingual education (pp. 125-135). Ypsilanti, MI: Michigan University.

Hakuta, K. (2001). The education of language minority students. Testimony to the U.S. Commission on Civil Rights. Retrieved April 13, 2001, from www.stanford.edu/ hakuta/Docs/CivilRightsCommission.htm

Hamers, J. F. (1981). Psychological approaches to the development of bilinguality. In H. Beatens-Beardsmore (Ed.), Elements of bilingual theory (pp. 28-47). Brussels, Belgium: Vrije Universiteit te Brussel.

Hoffman, M.L. (2001). A comprehensive theory of prosocial moral development. In D. Stipek, \& A. Bohart (Eds.), Constructive and destructive behavior (pp. 61-86). Washington, D.C.: American Psychological Association.

Jacobson, T. (1979). Social implications of intra-sentential code-switching. In J. Amastae, \& L. Elias-Olivares (Eds.), Spanish in the U.S.:

Lambert, W.E., \& Tucker, G. R. (1972).The bilingual education of children: The St. Lambert experiment. Rowley, MA: Newbury House.

Lauren, C. H. (1994). Preface. In C. H. Lauren (Ed.), Evaluating European immersion programs: From Catalonia to Finland. Proceeding of the University Vaasa. Research Papers, 185(27).

Macnamara, J. (1967). The bilingual's linguistic performance: A psychological overview. Journal of Social Issues, 23, 58-77. https://doi.org/10.1111/j.1540-4560.1967.tb00576.x

Marinova-Todd, S. H., Marshall, D. B., \& Snow, C. E. (2000). Three misconceptions about age and L2 learning. TESOL Quarterly, 34, 9-34. https://doi.org/10.2307/3588095 
Rebuffot. J. (1993). Le Point sur l'Immersion au Canada. Anjou, QC: Centre éducatif et culturel.

Skutnabb-Kangas, T., \& Toukomaa, P. (1976). Teaching migrant children's mother tongue and learning the language of the host country in the context of the sociocultural situation of the migrant family. Report written for Unesco. Tampere: University of Tampere, Dept of Sociology and Social Psychology, Research Reports.

Swain, M., \& Johnson, R. K. (1997). Immersion education: A category within bilingual education. In R. Johnston, \& M. Swain (Eds.), Immersion education: International perspectives (pp. 1-16). Cambridge, England: Cambridge University Press. https://doi.org/10.1017/CBO9781139524667.003

Swain, M., \& Lapkin, S. (2005). The evolving sociopolitical context of immersion education in Canada: Some implications for program development. International Journal of Applied Linguistics, 15(2), 169-186. https://doi.org/10.1111/j.1473-4192.2005.00086.x

Titone, R. (1989). The holodynamic model of language learning. The Canadian Modern Language Review, 1 , $10-21$.

\section{Copyrights}

Copyright for this article is retained by the author(s), with first publication rights granted to the journal.

This is an open-access article distributed under the terms and conditions of the Creative Commons Attribution license (http://creativecommons.org/licenses/by/4.0/). 